\title{
6. Do Governments Suffer from Political Myopia: What is the problem and what can be done about it?
}

\author{
Robyn Kruk and the Honourable Sir Michael Cullen
}

\section{Robyn Kruk}

The former US President Bill Clinton was fond of saying that he was always an optimistic, 'glass half-full' person, because he took pessimism to be an excuse for inaction. And while I occasionally express cynicism about governments and ministers, I am generally positive about ongoing change and the need for change, but also realistic about the challenge of the task.

I speculate that I was probably asked to address this topic because I have run the NSW health agency (Australia's largest) and both the State and national environment agencies. In the health agency, State treasury officials too often considered me the cause of their deficit problems and said if I could only get the budget in order there would be no problems across the rest of the State budget. Alternatively, when I was an environment head it was the 'green tape' introduced by the agency that was allegedly responsible for the poor state of accounts of the country. So both agencies always considered themselves very much the 'Nigel no-friends' of the Government. Ironically enough, the tenures of CEOs in my position are usually among the shortest in government. The average length of tenure of a health CEO is approximately 18 months. The only tenure shorter is that of health ministers. In the five years I was the CEO of NSW Health I worked with three ministers and all were convinced or had suspicions that their appointments were the result of a plot within their own party to knock them over. It was a similar story in the environment area.

So, my starting point for this chapter is: to what extent is political myopia a systemic problem and what can be done about it? I wish to begin by questioning the suggestion that political myopia is something new and has arisen only because of the Global Financial Crisis, and that the myopia problem and lack of foresight are linked only to the public sector. I would contend that both of these are misconceptions.

The policy sectors of health and environment are interesting because they tend to have boom and bust cycles. Both are areas that people care about significantly 
and are among the top issues that come up as being matters of public concern; certainly health comes up normally in the top two or three, while the environment ranks normally in the top six, although that can vary depending on economic circumstances. They are also policy sectors where political parties tend to seek to differentiate their product. Both may rely on great technical complexity for their arguments. Both are areas that attract very broad interest and have been subject to deliberate media campaigns that seek to sway public opinion. Whether it is a story about what damage has been done in the health system or an environmental issue, both are very prominent in media circles.

Environment budgets have been taking an absolute battering in recent times, even in Canada and Australia, which have had relatively robust balance sheets. Both health and the environment tend to vacillate, with periods of cuts and austerity followed by systemic failures, scandals and inquiries, which then subsequently lead to injections of significant capital.

So, is political myopia a problem? Yes it is. Is it unique to government? I believe strongly it is not. Is it a new phenomenon? Again, no. And it is not solely the fault or responsibility of politicians. Foresightedness is difficult to achieve; so I want to mention some of the experiences that have worked for me in my various roles in government.

When studying public policy it is often said that if people do not care about an issue then politicians do not need to care either. But I have already argued people care for both health and the environment and there are plenty of quantitative studies to support that contention - so why do we find political myopia in these instances and how can we seek to future-proof their budgetary requests? Clearly the public's expectations are high in these policy areas and I would say that certain forms of myopia have developed precisely because those expectations have not been successfully dampened.

For instance, I recall a former NSW treasurer who used to open the budget committee every time the health minister and I appeared, by saying, 'I'm short, fat, bald and ugly and what's the government going to do about it? Oh, here are the health officials.' That statement concisely encapsulated a whole range of challenging health budget issues, including expectations about a nanny state or the very deliberate promulgation of the latest medical advances and latest medical technology. It included the belief that one can live forever, one can look forever youthful, that there is a silver bullet for every disease or malady. Those expectations have not been dampened. In fact they are actively promulgated in commercial and social media. So is there a form of myopia attributable to those expectations? Yes, I believe so, but we probably all share in those expectations and help create them. 
The related issue to address is the question of what assists to perpetuate those expectations. One of the things that troubled me most as health CEO was that despite the fact that health was one of the few agencies to receive additional monies, the growth in demand meant it was still operating in a structural deficit at any point in time. But the expectation created in the community was that health was getting new money and additional services would be provided, and there would be no cutbacks in services. Hence, one of the key issues in expectation management was that many budget announcements and political processes actually stoked the expectation that there was additional money. That, in effect, fed what we used to call in the health area the 'a-ort-a syndrome': 'they (the government) ought to do something about that.'

That was probably the biggest issue that beset us most frequently in the media. And it was hardest to counter if there had been massive build-up of expectation because new monies were apparently being provided. Accordingly, I would suggest first that it is easier in many ways to initiate reform, lead service configuration changes and lead policy changes where there is an overwhelming perception that there is a climate of austerity and the facts support the view. The most difficult situations I have had in terms of future-proofing budgets and making them sustainable are where changes are made without knowing the impact or giving any consideration to the likely impact. Across-the-board budget saving targets are illustrative.

The second issue that perpetuates some of the difficulty in future-proofing a budget is where policy proposals are devised and initially introduced to the community in the form of green or white papers. These are all too often silent on the proposed source of funds. Yet, if word gets out, it is normally reported in the media that the initiative is already being introduced, whereas in reality it has merely been floated as an idea in the traditional Westminster bidding mode of cabinet. The process, in effect, increases the risk of a 'run on the bank'; it increases the public's expectations, and thereby makes a long-sighted approach far more difficult.

The third issue is that when treasurers make budget announcements, the tendency has increasingly been to announce only the increases in expenditure - which may in fact most often be funded by offsets or redirected monies or reinvestments from other areas. Yet in making those new funding announcements, treasurers neglect to announce the areas from whence the funds are being redirected. So people again are given the expectation that there is additional money.

The final point - one I notice is shared with Canadian and British colleaguesis that there is supposedly a move to provide greater flexibility to directorsgeneral. Yet directors-general (or CEOs or departmental secretaries, whatever the title) are provided with fiscal discipline targets accompanied normally with 
some quite stringent and counterintuitive directives such as: 'There will be no loss of frontline staff; there will be no closure of services; there will be no bad media in my patch. If you get some negative media in my colleagues' patches, that is a bonus.' Some tight strictures are issued in terms of how the cuts may actually be manifested. These are the types of issues that I would describe as the challenges I faced in future-proofing budgets, and I am sure many others have faced similar ones.

Health has traditionally been somewhat quarantined from cuts because there have regularly been some additional monies provided, but to future-proof health the equation arguably needs to be changed. Some funding mechanisms or payment regimes can have the perverse effect of driving demand. For example, a 'fee for service' focus rather than an 'episode of care' focus has fundamental impacts for future health budgets and health outcomes more generally. We need to ask how the incentives and funding regimes for new activity are to be structured, whether through direct government funding (including transfers between the Commonwealth and the States), through co-payments from patients to physicians or on the achievement of health outcomes - or to challenge expectations that we can all live beautifully forever.

In my health budgets only 2 per cent was directed towards preventative health measures while 98 per cent was directed towards chronic and acute services - a major imbalance and a poor long-term investment scenario. If we want to ensure health expenditures are sustainable and future-proof the policy sector then we need to divert money from the acute machinery into the preventative area. Is this a feasible long-term strategy? I would argue that it is but readily acknowledge that it is not without significant political challenges. I will suggest five things that will help make these long-term changes.

First, we need to institutionalise foresighted reporting. In Australia, Ken Henry, the former treasury secretary, released a series of seminal intergenerational reports that actually encouraged long-term thinking and debate. They put risks and opportunities on the policy agenda and have become a major resource for the public sector, for industry and also for the media.

Second, transparent reporting is needed. In my areas of work, some of the most incredibly powerful, well-orchestrated interest groups in the climate change area and in the health technology area are well cashed to push a particular argument to make life quite difficult for ministers or governments.

In the health sector, the move that made the most significant changes in my experience was the creation of a statutorily based, transparently focused and independent reporting function - one that is separate from the health administration system. The issues need to be reported on independently, 
regularly and accessibly and be less vulnerable to mistranslation or a bipartisan presentation. Such reporting needs to be robust throughout government. We take for granted that the Australian Bureau of Statistics reports on the economic wellbeing of the country, including social and mental wellbeing. While it is sensible to have the accounts of the country pick up the people issues and look at the effects on resource use and exploitation, such reporting needs to be hardwired into government to make them the backdrop to discussions.

Third, in terms of the quality and integrity of health services, most health systems have now moved to transparent reporting of so-called avoidable events that impact on patient safety; however, this was not always the case. The most difficult issues that the health minister faced day-by-day were often perpetuated by a pattern of not releasing quality and safety data. By totally shifting our focus and instituting an independent, regular reporting structure on how many people were damaged, injured or subjected to avoidable, adverse events the game changed significantly and the information provided was considered to be more reliable. That is not to say that this transparency did not put considerable pressure on the health minister. I remember after the first such report I said to him, 'You have to go out tomorrow and say, "This number of people have died or been seriously injured in the health system", but then you have to say "We've also underestimated that number".' The minister said, 'You have to be joking!' The issue was that this reporting introduced a transparency in the health system and totally changed the nature of the debate in the media. It provided an insight into health care that was more complex than an argument about dollars, which always suggests a simple, short-term fix or solution is possible.

In relation to the media some political circles are lagging behind the population. The next generation of voters does not read newspapers, but politicians still respond to the Daily Telegraph as if it presents the facts. Actually, the NSW Bureau of Crime Statistics and Research, which is part of the NSW AttorneyGeneral's Department, is considered one of the most credible and accepted resources in relation to true crime statistics, yet, because it is not a newspaper, its data remain unread, unknown and largely ignored. So it is necessary to hardwire some of the hard research data into the policy backdrop.

Furthermore, citizens show no greater trust of bureaucrats than they do of politicians. There is suspicion of officials and their motivations. For instance, I could have far more influence in the health debates and in the media by getting some clinicians in white coats to present an argument than I ever could by making a statement. Pick the right people to proffer your debates. A minister fronting the media in relation to a patient safety event immediately politicised the issue and guaranteed ongoing and ill-informed press. If a doctor addressed the issue and acknowledged 'this is terrible, I can relate to it personally, it is not acceptable', the issue would die quickly in the 24-hour media cycle. So it 
is also a matter of being a bit more responsive in the bureaucracy to looking at an active role in 'issues management' as opposed to having politicians always fronting up and then being surprised when they basically roll over.

Fourth, recognise that the bureaucracy has a significant role and one highly dependent on both political and public trust. Hilary Mantel's 2009 book Wolf Hall presents an interesting insight into the historical relationship between the government and the bureaucracy and I encourage you to read it. It concerns the relationship between Henry VIII and Sir Thomas Cromwell. It looks at the politics of the royal court, but an underpinning sentiment is the importance of trust in the relationship with the bureaucracy.

Members of the bureaucracy have devoted their careers to understanding some of the most complex matters and putting forth proposals to futureproof the department. It is important always to be aware of what is within the department's control and what can be done to promulgate a change in the public debate and the potential impact on political capital for the minister or government. Westminster bureaucrats too often think it is for the minister alone to promulgate the case for change and to play the so-called long game at the cost of short-term gains. If I relied on a minister to promulgate the case for change it would not have occurred in many instances. Future-proofing budgets is ultimately a shared responsibility. Similarly, it would be naive to expect a minister to risk sacrificing their career on the basis of bureaucratic advice alone without an appreciation of the potential support or criticism for a less myopic view. The issue of trust in this situation is quite significant.

The final thing that will reduce myopia is that the line between so-called political research and public sector policy research has become greyer-particularly in relation to social research. This is not necessarily a bad thing. The investigatory work we did in both health and the environment to get a better understanding of the fundamental issues that concerned the community, and to use it as a proper basis for engagement with the community, was significant in introducing some long-sighted strategies the health area needed. Now, those policy challenges do not disappear. They are qualitatively different from instantaneous political polling of opinions, but it meant that we had to maintain a capacity with health to undertake matters that were separate from managing the issue of the day. This allowed the department to separate the fact that people needed to have long-sighted strategies as their primary focus and that managers needed to make decisions about the priority of those people over and above some strictly organisational functions.

In summing up, the whole narrative of austerity makes future-proofing budgets a lot easier largely because of the potential impact on public expectations. Governments and bureaucracies have developed a holistic focus, and share a 
common language and a level of understanding and awareness about some of the difficulties we face; however, transparency and independent reporting are critical even though the organisations that do them may become the subject of cuts, too. In the United Kingdom there were reported cuts to their Office for National Statistics and to their Office for Budget Responsibility. Areas that were clearly given the task of reporting honestly on the situation were in many instances having to report bad news. It shows inversely the critical importance of those agencies.

\section{The Honourable Sir Michael Cullen}

One of my former Labour colleagues, Mike Moore, would sometimes pose a question when we were getting carried away, saying rhetorically, 'What's posterity done for me?' That's a question politicians can ask themselves in many respects. It is a question that may suggest why we descend into a kind of myopia about what governments can be expected to deliver. But it also implies that the core problem is simply related to 'elected governments' when the root problem probably lies much deeper than that. By that I mean the case can be made that politics and governments tend to deal in the short term and struggle to come to grips with the long term, but that phenomenon is not confined to, or even most evident among, politicians. In fact, politicians who try to deal with long-term issues nearly always find themselves in conflict with pressure groups which benefit from the status quo and with a largely uninterested public - especially if there are more immediate pressures vying for attention, such as economic ones. And when don't such pressures loom large for the ordinary person?

I would like to make two preliminary points. Above all, politicians now face a media whose interest barely extends beyond the immediate news cycle, which is roughly one hour. Media comment is seldom around the inherent value of policies. In many cases it is often hard to find out what the policy is from media coverage because its comment is usually about how the policy is going to be received by the public, not about what it is and to what extent it has neutered the opposition.

The media's underlying assumption with any long-term announcement is that it is intended to be a diversion from immediate issues; and in any case those making the announcement cannot be made accountable for the outcome because they will not be there when the outcome occurs or does not occur. Those are the attitudes found among the quality end of the media; but there is also a world called 'talkback radio', which cynically trivialises everything or demands instant gratification. 
In other words, it is a little unreasonable in a world of instant comments and pervasive cynicism to expect that politicians will be the one group focused on the long term - and that they should do what is considered right, take the electoral consequences and disappear into the holy glow of a grateful future. This ignores reality. All too often what that actually means is their political opponents are elected, they then overturn the policies, and, worst of all, your own former colleagues abandon these same policy principles because it makes them unelectable. That is what is likely to happen over carbon taxation at the 2013 Australian election.

The other preliminary point to make is: I question the assumption that democratic governments are particularly prone to systematic 'short-termism'. I see not the slightest evidence of that in relation to the big questions such as climate change, demographic transformation, ecological diversity, indigenous rights, economic sustainability or any other planet-saving issue. It would be very hard to argue that non-democracies are generally doing better than democratic societies in that regard. Rather the evidence tends to point in the opposite direction. China is now the largest emitter of carbon dioxide in the world and, no doubt, India will soon follow behind. In so far as democracies tend to be more polluting societies, that is simply because they are richer societies.

In democracies there is some evidence that where the electorate's attitudes are based more on rational principles and display greater international awareness they also tend to be more open to policies that help future-proofing. And that may just be a rather ponderous tautology. The real knotty problem about democracy and the prospects for future-proofing is that there is often an inherent contradiction between the two. Let me illustrate that with a vivid example, which you may appreciate more than some of the audiences ever did in my previous job as New Zealand's finance minister.

For much of the past 30 years New Zealand's purist classical liberals and their political associates have been trying to use legislation to prevent a socialdemocratic government adopting fiscal policies consistent with its principles. And that was pretty much the stated purpose of the author of New Zealand's Fiscal Responsibility Act of 1994: it was meant to lock in the conservative policies of the then minister of finance in New Zealand for the long term.

Treasury prevented such an outrage against democracy by ensuring that once the rhetoric was stripped away, the Act was in fact basically about more openness in fiscal intentions. As such it has proved very useful and I was able to incorporate it into the Public Finance Act with some amendments. 
The fact is that in democracies the people must be allowed to decide and get it right or wrong, or there is no democracy. Obviously, New Zealand Labour believes the people got it wrong in 2008 at the election that removed the Clark Government but there was no appeal against that judgment.

Such statements about parliamentary sovereignty need qualification in a number of ways, not least in relation to fundamental human rights. There are things that should not be subject to temporary passing majorities. The search for legislative or judicial bulwarks against bad judgment is not just a futile but also a profoundly elitist agenda and one for which the left is just as culpable as the right on occasions.

Let me not be misunderstood. I am not arguing for a passive acceptance of the failure to address the kinds of issues to which I have referred. The current weakness of international action on climate change is a clear case of collective pusillanimity in the face of a real common danger where defined and obvious solutions are conceivable and available. Not quite as bad is the fact that, so far, international finance capitalism has emerged from the Global Financial Crisis practically unscathed, having successfully socialised the cost of its failures, greed and incompetence, at a terrible cost to present and future generations; and indeed some are now trying to find ways to blame governments for the problem rather than the real authors of it.

So it will be no surprise that my argument is that what can be done that is both effective and consistent with democratic processes is relatively limited and may be far from sufficient to achieve a refocusing on the long-term big issues. And that refocusing will only come about when there is a sufficient groundswell of public support for it. The challenge is how best to assist in framing public understanding in a way that may generate that support. That is the real challenge to be faced.

The first part of the answer is to do better what we do already. Following up on one of Robyn Kruk's points, that means, for example, continuing to increase the level of openness about what the government has decided, how they did it and why they did it, and extending that to what the government is doing at present. It means generating more open and informed debate about the underlying principles and realities. In other words, increasing public understanding of what the relevant factors are in decision-making may assist in support for better decision-making. The one caveat to bear in mind, however, is that unfortunately the media tends to sensationalise any discussion about options. That tends to lead to foreclosing the options immediately as politicians run to the corner of safety, saying: 'No, we've ruled that out because of course if we don't all hell is going to break loose.' I get quite amused, I must say, when I read the rewriting of history on New Zealand's Foreshore and Seabed Act, which completely misses 
the way the media reaction to the court decision constrained almost entirely the options open to the government of the day in dealing with that issue. We have now arrived at a happier place in that regard.

Alongside that greater openness runs a stronger emphasis on articulating the long-term fiscal framework and pressures. New Zealand has already been in the forefront, having pioneered some of these exercises already. At present Treasury is working with a number of us towards the new long-term fiscal framework commencing probably next year. But here again we need a more responsible approach by the media in not sensationalising the outcomes of such information provision; otherwise it becomes counterproductive.

The third way of framing public understanding to strengthen support for longer-term issues in public policy is to adopt a range of measures of social and economic performance that encourage long-term thinking. It is now well established that the primary measure we use, gross domestic product (GDP), encourages resource depletion rather than sustainability and encourages energy production and consumption rather than efficiency and conservation. It would be fascinating using such different measures to compare Australia's GDP with New Zealand's GDP, given the degree to which Australia depends upon resource depletion. A broader national accounting system may give quite a different picture about the comparison of the two countries and the trends over the past 20 or 30 years. Helping people understand that we are consuming our future at an unsustainable rate may assist in support for the kind of paradigm shift the world needs.

The fourth is to create, or recreate in New Zealand's case, an institution with power to engage in long-term future thinking across the board and to collaborate with like-minded institutions in this area. And rather than sitting in splendid but weak isolation, and therefore likely to be staffed by people favourable to whatever the current government's general philosophy is, such a body should be hosted in one or more of our universities. In particular, it would be a useful counter to the number of bodies which push short-term growth agendas with no sustainable long-term considerations. There is no countervailing influence, certainly in New Zealand, at the present time, in that regard.

As a final suggestion, I would argue we are well overdue for a full review of commercial legislation, accounting principles and the like to see how the current regimes favour 'short-termism' and how they could be changed to provide a better focus upon the long term. It is not just a matter of detail-for example, we are now required to have quarterly profit reporting in the public sector, which sees agencies focus upon every quarter's profit rather than a longer-term 
picture. But the whole mindset that underlies the way we approach these issues in the commercial sector suggests you will probably find at least as much shortterm thinking as you will find in the political sector in societies such as ours.

Recently, I had a debate with Treasury. The standard measure of labour productivity calculates the output per worker employed. That sounds sensible. The problem is that if you have a strongly growing economy, where unemployment is dropping, average labour productivity falls. It looks as though you are doing worse economically. Logically, in an economy where workers are laid off and mass unemployment is rising, labour productivity numbers will go up as a consequence. So in fact if you were to measure labour productivity by the output per person in the whole workforce, as opposed to merely those in employment, you might get a better statistic on which to base decisions. If you have to make a choice between 100 per cent being employed with, say, a 90 per cent productivity rate and a 90 per cent employment and 100 per cent productivity rate, the only reason we would choose the latter rate is because Australia, with its higher wages, is sitting opposite us and takes our people. On any rational grounds you would choose the 100 per cent employment option. Socially it is a far better outcome than having 10 per cent unemployment. It is not a stupid example because many European countries were stuck before the Global Financial Crisis with high levels of unemployment, but apparently high productivity levels. That is not a socially desirable outcome.

That brings it back, then, to my earlier point: 'short-termism' is not a unique feature confined to politics and is not even at its worst amongst politicians. Politicians are doing what they are meant to do. They are responding to public demand and to the rewards that are available to them in that regard. If there is no reward for thinking long term then politicians are much less likely to do so. I know it comes as a terrible shock to some people, but when you are actually in government you want to get re-elected to government. Politicians do not see their role in life as being to hand over to opponents on some sort of rotatingturn principle of who should be actually governing the country.

'Short-termism', however, is also evident among the general population in many countries. I do not know how many long-term issues most people can grasp at once and deal with, because when they start adding them up they become overwhelming. People say, 'We're going to get old; we won't be able to afford health care; we can't afford the pension; and in any case if you live less than two metres above sea level you will be in deep trouble if you're going to live more than another 10 years', and so on. And for resigned escapists who decry the real world, they think: 'Well, so what?' People quickly retreat into a kind of short-term nihilism if they are faced with too many protracted long-term issues 
presented in a way in which there are no simple solutions. The terrible thing is that in most of these areas there are actually relatively simple solutions if we can get the debate framed in an intelligent fashion.

At heart I believe the real challenge is to convince a sufficiently large number of people that our patterns of behaviour must change. But do not confuse this with the notion that I am preaching a gospel of 'sackcloth and ashes' and making people feel guilty about the relatively modest affluence most enjoy in our societies at present. All too often radical green groups in particular fail to realise the need for an approach that is people-friendly and prosperity-friendly. Selling the idea to people that we are going to become worse off, or that a shrinking pie will be more equally divided up, is a heroic political enterprise that is not capable of fulfilment in a democratic society. Behavioural change is the most important challenge to be met but we have barely begun the task of doing so at present. 
This text taken from Future-Proofing the State: Managing Risks, Responding to Crises and Building Resilience, edited by Jonathan Boston, John Wanna, Vic Lipski and Justin Pritchard, published May 2014 by ANU Press, The Australian National University, Canberra, Australia. 